\title{
Various aspects of Kikuchi disease in three children: systemic or self-limited disease?
}

\author{
L Goffin ${ }^{1 *}$, S Huybrechts ${ }^{1}, C_{\text {Heijmans }}{ }^{1}$, AS Bouteiller ${ }^{1}$, C Thomée $^{2}$, V Segers ${ }^{3}$, MF Dehou ${ }^{3}$, A Ferster ${ }^{1}$ \\ From 18th Pediatric Rheumatology European Society (PReS) Congress \\ Bruges, Belgium. 14-18 September 2011
}

Kikuchi's disease (KD), or histiocytic necrotizing lymphadenitis, is a rare benign and self-limited disease involving young adults, predominantly females. It is rarely described in children. It is characterized by localized lymphadenopathy, often associated with fever and systemic symptoms. The diagnosis is based on histological examination of lymph node biopsy. The disease usually resolves spontaneously over a period of several weeks to months. In some cases, KD reveals or evolves into a systemic lupus, reason why long term follow-up is recommended.

Three cases of pediatric KD are presented in Table 1.

In conclusion, KD is rarely observed in children, has various presentations but usually favorable outcome. This small cohort of pediatric patients illustrates this diversity: one of them presented with marked systemic symptoms, suggesting SLE but resolving after prolonged corticotherapy, while the others had a more benign

Table 1

\begin{tabular}{|c|c|c|c|}
\hline & Patient 1 & Patient 2 & Patient 3 \\
\hline Age (years) & 5 & 17 & 9 \\
\hline $\begin{array}{l}\text { Underlying } \\
\text { disease }\end{array}$ & $\begin{array}{l}\text { Non complicated sickle cell } \\
\text { anemia }\end{array}$ & Severe sickle cell anemia & None \\
\hline Symptoms & $\begin{array}{l}\text { - Left cervical } \\
\text { lymphadenopathy } \\
\text { - Intermittent fever }\end{array}$ & $\begin{array}{l}\text { - Intermittent fever } \\
\text { - Maculo-papules } \\
\text { - Fatigue } \\
\text { - Painful cervical and inguinal adenopathies } \\
\text { - Headaches } \\
\text { - Polyarthritis }\end{array}$ & $\begin{array}{l}\text { - Prolonged fever } \\
\text { - Intermittent tonsillitis } \\
\text { - Bilateral painful cervical lymph } \\
\text { nodes }\end{array}$ \\
\hline $\begin{array}{l}\text { Biological } \\
\text { features }\end{array}$ & $\begin{array}{l}\text { - Mild inflammation } \\
\text { - Elevated LDH }\end{array}$ & $\begin{array}{l}\text { - Marked inflammation } \\
\text { - Pancytopenia } \\
\text { - Auto-immune anemia } \\
\text { - Auto-immune hepatitis } \\
\text { - No ANA }\end{array}$ & $\begin{array}{l}\text { - Marked inflammation } \\
\text { - Leucopenia }\end{array}$ \\
\hline Biopsy & $\begin{array}{l}\text { Cervical lymph node } \\
\text { excisional biopsy }\end{array}$ & Cervical lymph node excisional biopsy & Tonsillectomy \\
\hline Treatment & None & $\begin{array}{l}\text { - Steroids for } 7 \text { months } \\
\text { - Azathioprine } \\
\text { - Methotrexate }\end{array}$ & None \\
\hline Outcome & $\begin{array}{l}\text { Spontaneous resolution } \\
\text { after } 4 \text { months }\end{array}$ & $\begin{array}{l}\text { Progressive regression of clinical and biological signs with } \\
\text { resolution of auto-immunity }\end{array}$ & $\begin{array}{l}\text { Spontaneous resolution } 2 \text { months } \\
\text { after tonsillectomy }\end{array}$ \\
\hline
\end{tabular}

\footnotetext{
* Correspondence: laurence.goffin@huderf.be

'Department of Pediatry, Hôpital Universitaire Des Enfants Reine Fabiola,

Brussels, Belgium

Full list of author information is available at the end of the article
}

C Biomed Central

C 2011 Goffin et al; licensee BioMed Central Ltd. This is an open access article distributed under the terms of the Creative Commons Attribution License (http://creativecommons.org/licenses/by/2.0), which permits unrestricted use, distribution, and reproduction in any medium, provided the original work is properly cited. 
course with spontaneous resolution after excision. Association with sickle cell disease has not been described and, to our best knowledge, this is the first case diagnosed on tonsil examination.

\section{Author details}

${ }^{1}$ Department of Pediatry, Hôpital Universitaire Des Enfants Reine Fabiola, Brussels, Belgium. ${ }^{2}$ Department of Pediatry, Centre Hospitalier de

Luxembourg, Luxemburg. ${ }^{3}$ Department of pathology, CHU Brugmann,

Brussels, Belgium.

Published: 14 September 2011

doi:10.1186/1546-0096-9-S1-P235

Cite this article as: Goffin et al:: Various aspects of Kikuchi disease in three children: systemic or self-limited disease? Pediatric Rheumatology 2011 9(Suppl 1):P235.

Submit your next manuscript to BioMed Central and take full advantage of:

- Convenient online submission

- Thorough peer review

- No space constraints or color figure charges

- Immediate publication on acceptance

- Inclusion in PubMed, CAS, Scopus and Google Scholar

- Research which is freely available for redistribution

Submit your manuscript at www.biomedcentral.com/submit 